\title{
A bizarre object to swallow
}

\author{
Abdul-Wahed Nasir Meshikhes, ${ }^{1}$ Qassim Al-Dolah ${ }^{2}$
}

${ }^{1}$ Department of Surgery, King Fahad Specialist Hospital, Dammam, Saudi Arabia ${ }^{2}$ Department of Surgery, Dammam Central Hospital, Dammam, Saudi Arabia

\section{Correspondence to} Dr Abdul-Wahed Nasir Meshikhes,

meshikhes@gmail.com
To cite: Meshikhes A-WN, Al-Dolah Q. BMJ Case Rep Published online: [please include Day Month Year] doi:10.1136/bcr-2013201296

\section{DESCRIPTION}

A 35-year-old mentally retarded man was admitted with a 3-day history of epigastric pain, vomiting and feeling of fullness. Clinically, he was pale, but was not in distress and his vital signs were normal. Abdominal examination revealed deep tenderness and a palpable mass in the epigastrium, but no guarding or rigidity. Routine blood tests were normal, except for irondeficiency anaemia. Abdominal X-rays showed a foreign body occupying the stomach (figure 1). Attempted endoscopic removal failed. The patient underwent an exploratory laparotomy, which showed

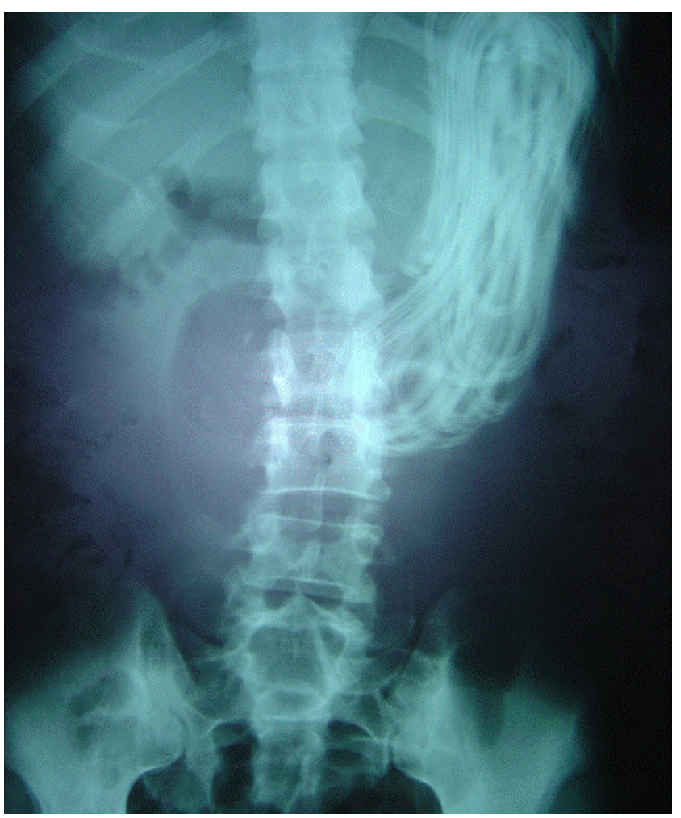

Figure 1 Plain abdominal X-rays showing a foreign body occupying the gastric lumen. a hard mass within the gastric lumen. The stomach was opened by gastrotomy and the foreign body was removed (figure 2). After washing and unfolding of the objects, it was identified as four door frame rubber seal strips and one metallic ruler (figure 3). He was discharged 5 days later and was well at 6-month follow-up.

Bezoars are concretions of foreign materials that accumulate in the stomach or intestine. ${ }^{1} \mathrm{~A}$ bezoar can be made of hair (trichopbzoars), fruits and vegetable fibres (phytobezoars) or any indigestible material. ${ }^{2}$ Swallowing of foreign bodies, is considered part of a personality disorder syndrome, and is commonly encountered in mentally retarded individuals. The world literature is rich with many reports of bizarre swallowed objects. However, this may well be the first case of ingested long door rubber seal strips.

The management in most cases of bezoars is conservative and 'watchful waiting', as most swallowed foreign body will pass naturally or can be left for several years. Surgical intervention is reserved for complications such as perforation, bleeding or obstruction. $^{3}$

\section{Learning points}

- Ingestion of bizarre foreign objects is commonly encountered in mentally retarded individuals.

- The management in most cases of bezoars is conservative and 'watchful waiting'.

- Surgical intervention is reserved for troublesome symptoms and complications such as perforation, bleeding or obstruction.
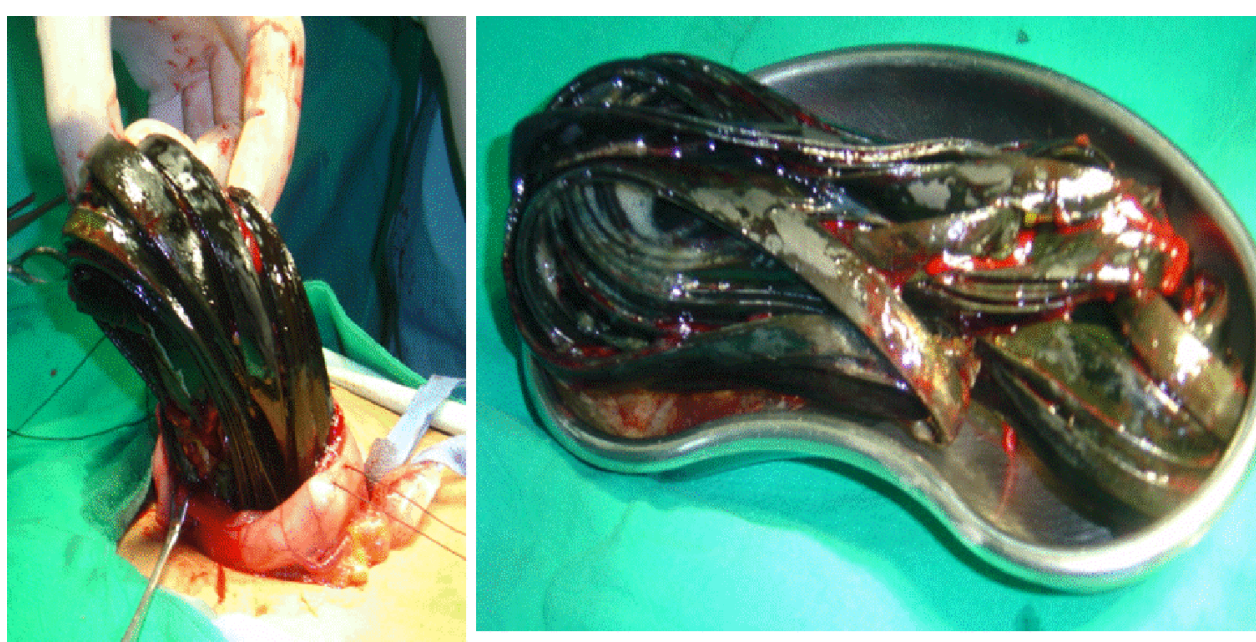

Figure 2 Operative view of the removal of the foreign body through a gastrotomy (left) and the retrieved foreign body (right) 


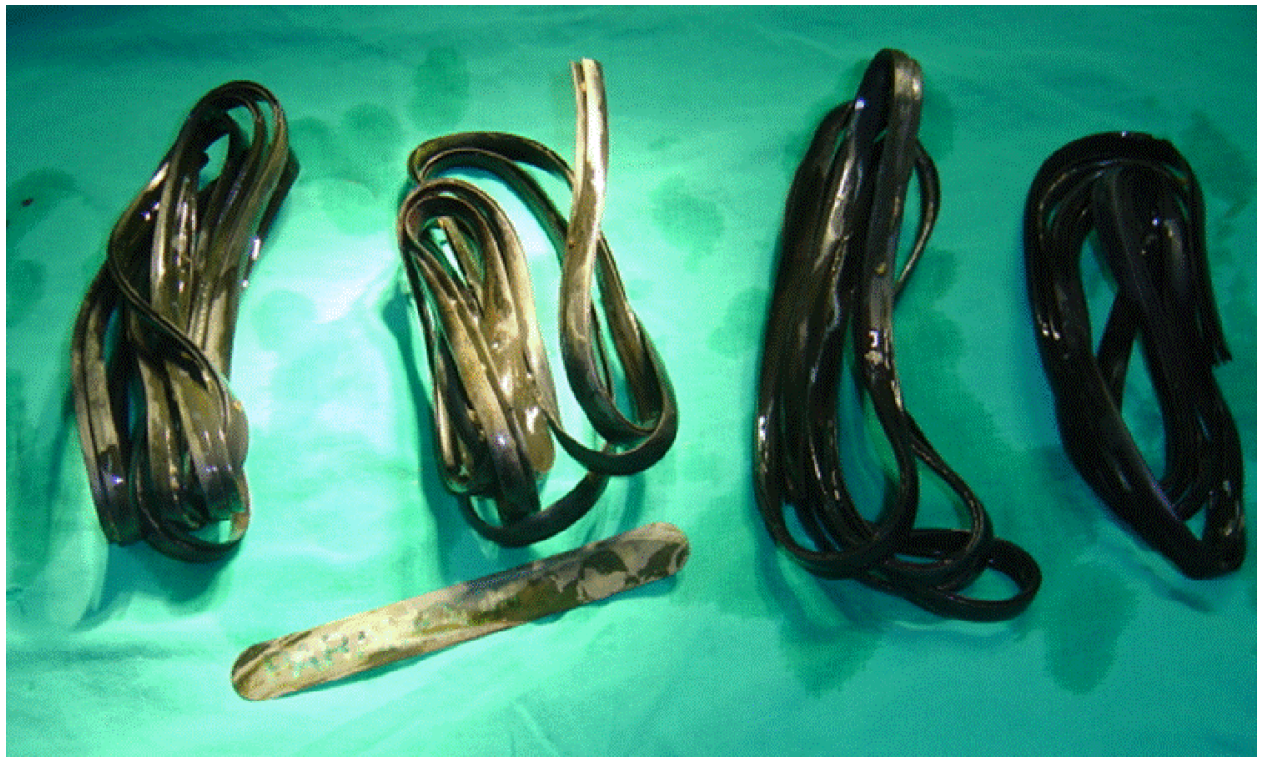

Figure 3 The washed foreign body: four rubber seal strips and a metallic ruler.

Contributors A-WNM managed the case and wrote the final draft and QA-D searched the literature and helped in writing the initial draft.

\section{Competing interests None.}

Patient consent Obtained.

Provenance and peer review Not commissioned; externally peer reviewed.

\section{REFERENCES}

1 Macksey L. Aspirated bezoar in a pediatric patient: a case report. AANA J 2006;74:295-8.

2 Gonuguntla V, Joshi DD. Rapunzel syndrome: a comprehensive review of an unusual case of trichobezoar. Clin Med Res 2009;7:99-102.

3 Phillips MR, Zaheer S, Drugas GT. Gastric trichobezoar: case report and literature review. Mayo Clin Proc 1998;73:653-6.

Copyright 2013 BMJ Publishing Group. All rights reserved. For permission to reuse any of this content visit http://group.bmj.com/group/rights-licensing/permissions.

BMJ Case Report Fellows may re-use this article for personal use and teaching without any further permission.

Become a Fellow of BMJ Case Reports today and you can:

- Submit as many cases as you like

- Enjoy fast sympathetic peer review and rapid publication of accepted articles

- Access all the published articles

- Re-use any of the published material for personal use and teaching without further permission

For information on Institutional Fellowships contact consortiasales@bmjgroup.com

Visit casereports.bmj.com for more articles like this and to become a Fellow 